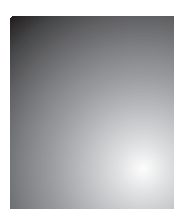

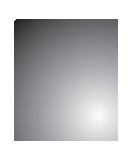

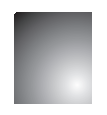

\title{
UMA ANÁLISE DAS RELAÇÕES ENTRE SUPORTE ORGANIZACIONAL E COMPROMETIMENTO DUPLO DE EMPREGADOS NO MODELO OUTSOURCING
}

\author{
An analysis of the relationship between organizational \\ support and dual commitment of employees in the \\ outsourcing model-academic category
}

Fabio Mendonça Martins Correio

Mestre em Administração. Fucape Business School. CIDADE, ESTADO. Brasil. E-mail: fabio.mendonca.martins@gmail.com

Bruno Felix von Borell de Araujo Correio

Doutor em Administração de Empresas. Fucape Business School. CIDADE, ESTADO. Brasil. E-mail: bfelix@fucape.br

\section{Resumo}

Neste estudo, busca-se explorar o fenômeno de relações de trabalho envolvendo distintas organizações, como o ocorrido em processos de Outsourcing que têm trazido maior complexidade aos vínculos afetivos entre trabalhadores e organizações, para melhor compreender a influência do porte da empresa empregadora na relação entre o Suporte Organizacional Percebido (SOP), oferecido por ambas as organizações, e o respectivo Comprometimento Afetivo (CA) obtido por elas. Identificou-se nesta pesquisa uma relação positiva entre os constructos Suporte Organizacional Percebido (SOP) e Comprometimento Afetivo (CA). Adicionalmente, o faturamento da empresa contratada moderou a relação entre estes dois constructos. $\mathrm{O}$ estudo apresenta algumas limitações: o modelo não considerou, por exemplo, a localidade do posto de trabalho no qual os empregados estão alocados (se nas dependências da contratante, da contratada ou em algum local diferente).

Palavras-chave: Suporte Organizacional Percebido (SOP); Comprometimento Afetivo (CA); Porte Empresarial; Troca Social; Outsourcing.

\section{Abstract}

In this study, we explore the labor relations phenomenon involving distinct organizations, as it occurs in Outsourcing processes which leads to greater complexity in affective ties between workers and organizations, so we can better understand the influence of the size of the employer on the relationship between Perceived Organizational Support (POS) offered by both of the organizations and their Affective Commitment (AC) obtained by them. In the this study, we identified a positive relationship between the constructs Perceived Organizational Support (POS) and Affective Commitment (AC). Additionally, the contracted firm's Revenue moderated the relationship between these two constructs. The study presents some limitations. The model did not consider, for example, the location of the workplace in which employees are allocated (whether in the premises of the contracting, contracted or another different place).

Keywords: Perceived Organizational Support (POS); Affective Commitment (AC); Business Size; Social Exchange; Outsourcing. 


\section{INTRODUÇÃO}

O aumento do fenômeno de relações de trabalho envolvendo distintas organizações, como o ocorrido em processos de Outsourcing, tem trazido maior complexidade aos vínculos afetivos entre trabalhadores $e$ organizações (VEITCH; COOPER-THOMAS, 2009). O Outsourcing é uma forma de relação trabalhista com características atípicas em relação aos modelos tradicionais de emprego, pois o trabalhador desenvolve relações de troca com duas organizações: a empresa empregadora, com quem possui um vínculo trabalhista, e a empresa cliente, que é a contratante dos serviços realizados no cotidiano (GEORGE; CHATTOPADHYAY, 2005). Ambas oferecem ao trabalhador algum nível de Suporte Organizacional, que é a atenção dispensada em relação ao seu esforço e bem-estar (BUTCHET et al., 2010) e obtêm dele algum grau de engajamento o qual o faz desejar permanecer vinculado à organização, o que aqui se chama de Comprometimento Afetivo (CA) (ALLEN; MEYER, 1996). Assim, o trabalhador no formato de Outsourcing realiza duas relações de trocas sociais simultâneas, de forma que é importante as organizações envolvidas compreenderem a dinâmica existente entre essas relações (GALLAGHER; PARKS, 2001).

Diante disso, diversos estudos (p.e., GIUNCHIET et al., 2015; BUCH et al., 2010; COYLE-SHAPIRO; MORROW, 2006; VAN BREUGEL et al., 2005; CONNELLY et al., 2007) têm sido dedicados a melhor compreender como organizações podem obter o comprometimento de trabalhadores em contextos de múltiplos vínculos organizacionais. Em geral, os resultados têm mostrado que trabalhadores com múltiplos vínculos de trabalho tendem a apresentar maior Comprometimento Afetivo (CA) quando interpretam estarem recebendo suporte organizacional, situação que está alinhada aos pressupostos da Teoria da Troca Social (BLAU, 1964). Adicionalmente, esses estudos também têm buscado ressaltar o papel que outras variáveis, como o tipo de contrato - temporário ou permanente (GIUNCHIET et al., 2015) - características culturais de ambas as empresas (EISENBERGER et al., 1990) e as motivações extrínsecas dos trabalhadores (DE JONG; SCHALK, 2010), exercem nessa relação.

Neste estudo, busca-se explorar uma lacuna a ser preenchida sobre esse tema. Faz-se necessário melhor compreender a influência do porte da empresa empregadora na relação entre o suporte organizacional oferecido por ambas as organizações e os respectivos comprometimentos afetivos obtidos por elas. $\mathrm{O}$ argumento defendido neste estudo é o de que quanto maior o faturamento da empresa empregadora, mais vinculado o indivíduo estará em relação ao seu empregador. Isto ocorreria pelo fato de que, como o comprometimento está fundamentado em uma noção de troca GÖBEL; VOGEL; WEBER, 2013) - ou seja, indivíduos tendem a se comprometer com organizações que eles entendem que estão aptas a recompensar sua dedicação (VEITCH; COOPER-THOMAS, 2009), é possível que em uma relação de múltiplos vínculos, variáveis de cunho financeiro, como o faturamento, atuem como um sinal de que a empresa possui potencial de oferecer reciprocidade ao comprometimento apresentado por indivíduos. Esse argumento se encontra alinhado com os pressupostos da Gestão de Múltiplos vínculos contratuais (FERNANDES; CARVALHO, 2005).

Assim, o objetivo do estudo é avaliar o papel moderador do faturamento da empresa empregadora na relação entre o Suporte Organizacional Percebido (SOP) e o Comprometimento Afetivo (CA). Mais especificamente são testadas duas relações de moderação realizadas pelo faturamento da empresa empregadora: a) uma entre o suporte organizacional oferecido pela empresa empregadora e comprometimento em relação a essa mesma empresa; e b) outra entre o suporte organizacional da empresa cliente e o Comprometimento Afetivo (CA) que o trabalhador possui em relação a essa empresa com a qual não possui um vínculo empregatício.

Este estudo contribui no sentido de fornecer às organizações uma resposta a cerca do nível ideal de estímulo e Suporte Organizacional a ser gerado pelas organizações aos trabalhadores, considerando que o Comprometimento Afetivo (CA) do trabalhador está suscetível ao porte da organização empregadora.

\section{Referencial Teórico}

Estrutura-se este capítulo a partir da apresentação da teoria de base do estudo, seguida de uma discussão dos constructos centrais e suas relações. Inicialmente, apresenta-se a Teoria da Troca Social (BLAU, 1964), 
que é apresentada aqui como uma lente que alicerça a relação entre os constructos estudados. Em seguida, destaca-se a relação entre o Suporte Organizacional Percebido (SOP) e o Comprometimento Afetivo (CA), conforme as particularidades da modalidade Outsourcing e, por fim, o Faturamento da empresa empregadora, aqui apresentada como moderadora da relação entre os constructos em questão.

\subsection{Teoria da troca social}

A Teoria da Troca Social possui suas raízes na economia clássica, antropologia e na psicologia (RANK; LECROY, 1983) e tem se mostrado como um paradigma influente para as relações de trabalho, dada a ampla aceitação de sua proposição central, que é a obrigatoriedade do ato de retribuir um favor recebido (BLAU, 1964). Esse conceito está diretamente ligado à reciprocidade nas relações (GÖBEL; VOGEL; WEBER, 2013), a qual se caracteriza por ser um tipo de interação social determinadora da forma como as organizações e os indivíduos atuantes nela se relacionam (COOK et al., 2013).

Segundo essa teoria, trocas sociais são relações de reciprocidade, nas quais atores sociais estabelecem uma relação de reciprocidade, na qual seus interesses são satisfeitos mutuamente. Assim, a interdependência se mostra como uma condição para uma troca social (CROPANZANO; MITCHELL, 2000). Um agente social pode ter pelo menos três diferentes posturas em relação aos outros com os quais se relaciona: interdependência, independência e dependência. A troca social somente ocorre em uma relação de interdependência, uma vez que a independência e a dependência se caracterizam como relações em que os resultados se baseiam nos esforços de apenas uma das partes. É a interdependência, caracterizada pelos esforços de ambas as partes que atingem os interesses de ambos, que caracteriza a fundamentação das relações de trocas presentes nas relações de trabalho entre empregadores e empregados (BLAU, 1964).

Uma "troca social recíproca", no entanto, se distingue de negociações típicas de processos de barganha situacional uma vez que a negociação envolvida na reciprocidade ocorre de forma mais implícita (CROPANZANO; MITCHELL, 2000). A interdependência implícita neste caso conduz a uma relação na qual se uma pessoa provê um benefício, a parte que o recebe deve responder oferecendo algo que satisfaça aos interesses e necessidades do outro (GERGEN, 1969), sem que o outro precise necessariamente barganhar para obter um resultado satisfatório para seus interesses. Dessa forma, uma "troca recíproca", baseada na reciprocidade, é vista como uma troca redutora do risco envolvido e encoraja a cooperação mútua (MOLM, 1994), de forma que enquanto uma parte oferece benefícios à outra, é esperado que naturalmente o recebedor devolva um esforço no sentido de satisfazer alguma necessidade do outro, sem ser necessária uma postura de barganha daquele que cedeu inicialmente (UHL-BIEN; MASLYN, 2003).

Apesar da ampla aceitação a essa ideia, a reciprocidade apresenta uma ambiguidade em sua definição e pode gerar variações na forma como empregados e organizações aplicam esses princípios (CROPANZANO; MITCHELL, 2005). Desta forma, é importante entender em que nível essas variações impactam as relações de trabalho em um ambiente de múltiplas organizações, considerando peculiaridades como o porte da empresa.

De acordo com Emerson (1976), essa proposição está diretamente relacionada à forma de empregado e organização interagirem, especialmente em um ambiente complexo e centrado na mutualidade, reconhecido como a base das relações sociais (GOBEL et al., 2013) e potencialmente capaz de gerar relações de qualidade (CROPANZANO; MITCHELL, 2005).

É importante destacar que tanto o empregado quanto as organizações envolvidas interagem entre si com objetivos individuais os quais não podem ser atingidos isoladamente (LAWLER; THYE, 1999), e transacionam neste ambiente múltiplo através de trocas de atividades tangíveis ou intangiveis, mais ou menos gratificantes e onerosas (HOMANS, 1961). Adicionalmente, é consenso entre economistas (GUTH, 1995; WILLIAMSON, 1993) e sociólogos (EMERSON, 1976) que, apesar de os objetivos serem individuais, a relação envolve cooperação e deve trazer benefícios para ambos.

Diante da importância da temática, sugere-se uma investigação mais profunda acerca dos fatores que levam o empregado a adotar distintos tipos de trocas sociais com as organizações com as quais interage simultaneamente, como no caso do Outsourcing. Neste estudo, delineia-se o interesse por analisar uma troca 
social específica: a reciprocidade existente na relação entre o suporte organizacional oferecido pelas organizações envolvidas em uma relação de Outsourcing e o Comprometimento Afetivo (CA) que os trabalhadores direcionam a essas instituições, como resposta recompensadora a esse suporte.

\subsection{Relação entre suporte organizacional percebido (sop) e comprometimento afetivo (ca) na modalidade outsourcing}

Diversos estudos têm analisado a relação entre o Suporte Organizacional Percebido (POS) e o Comprometimento Afetivo (CA) (EISENBERGER et al., 1986; GIUNCHI et al., 2015; EISENBERGER et al., 2001; EDWARD, 2009) sob a ótica de que trabalhadores tendem a apresentar maior Comprometimento Afetivo (CA) quando percebem que estão recebendo algum tipo de suporte organizacional (DE ALLEN et al., 1999; EISENBERGER et al., 1986; HUTCHISON, 1997; MEYER; ALLEN, 1997). Em geral, os estudos propôem que os trabalhadores irão apresentar maior Comprometimento Afetivo (CA) em troca do suporte fornecido pelas organizações (EISENBERGER et al., 1986).

Adicionalmente, empregados que se sentem suportados pelas organizações com as quais interage, estão propensos a desenvolver um forte sentimento de Comprometimento Afetivo (CA) como resultado deste apoio (p.e. RHOADES; EISENBERGER, 2002; SETTOON et al., 1996; SHORE; WAYNE, 1993; WAYNE et al., 1997), especialmente em um ambiente de interação com múltiplas organizações.

De acordo com Gallagher e Parks (2001), este ambiente de interação múltiplo proporciona ao trabalhador uma relação de troca social simultânea, onde ambas as organizações envolvidas precisam compreender a dinâmica existente entre esses dois constructos.

Nesta linha, compreender a definição entre estes dois constructos será importante para a pesquisa e contribuirá nas discussões a seguir: Suporte Organizacional Percebido (SOP) refere-se ao quanto os empregados percebem que as organizações com quem se relacionam estão preocupadas com o seu bem-estar e com a valorização das suas contribuições (EISENBERGER et al., 1986), enquanto o Comprometimento Afetivo (CA) reflete a identificação e o envolvimento emocional do empregado com as organizações com as quais se relaciona (MEYER; ALLEN, 1991).

Segundo Giunchi et al. (2015), o empregado pode interagir com a empresa empregadora e ao mesmo tempo com a organização cliente. Esta interação simultânea do empregado com mais de uma organização torna a compreensão dos processos inerentes ao Suporte Organizacional Percebido (SOP) ainda mais fáctivel, resultando em um maior comprometimento e empenho por parte do trabalhador, neste complexo ambiente de trabalho (LIDEN et al., 2003 apud BARAN et al., 2012). Além disto, uma melhor compreensão de tais relações poderá contribuir para o entendimento acerca das diferentes formas de as organizações gerarem estímulos aos empregados, especialmente na modalidade Outsourcing. Outros estudos também oferecem indícios de que o SOP pode estimular o Comprometimento Afetivo (CA), senso do empregado em pertencer àquele ambiente organizacional e do desejo de permanecer na organização (RHOADES; EISENBERGER, 2002; ESTIVALETE; ANDRADE, 2012).

Desta forma, encontram-se evidências de que possa haver uma relação positiva entre o Suporte Organizacional Percebido (SOP) da Empresa e o Comprometimento Afetivo (CA) em relação à empresa empregadora:

a) H1: O Suporte Organizacional Percebido da Empresa Empregadora (SOPEE) está positivamente associado ao Comprometimento Afetivo (CA) do trabalhador em relação a essa empresa

b) H2: O Suporte Organizacional Percebido da Empresa Cliente (SOPEC) está positivamente associado ao Comprometimento Afetivo (CA) em relação ao cliente.

\subsection{Faturamento da empresa empregadora como fator moderador}

Desde o estudo de Porter (1989) sobre vantagem competitiva, uma série de autores tem discutido a importância que o porte empresarial exerce no estabelecimento de vantagens (BONACCORSI, 1992; RIAHI-BELKAOUI; PAULIK, 1993; MOEN, 1999; ORSER; HOGARTH-SCOTT; RIDING, 2000) quando comparado a empresas de menor porte empresarial (PERIN; SAMPAIO, 2004). 
Diante disto, em um ambiente permeado por interações múltiplas, onde os objetivos são individuais e intransferíveis, fatores como o porte da empresa empregadora pode moderar a relação entre o Suporte Organizacional fornecido e o Comprometimento Afetivo (CA) apresentado pelo empregado, tornando-o mais ou menos suscetível aos estímulos gerados pela organização cliente.

Esse argumento encontra-se em linha com o pressuposto da Teoria de Suporte Organizacional (BARAN et al., 2012) e com os argumentos de Moen (1999), segundo os quais empresas de maior porte possuem mais recursos financeiros e tecnológicos para investimento no empregado, resultando em maior Comprometimento Afetivo (CA).

No entanto, se as relações entre o suporte organizacional e o Comprometimento Afetivo (CA) dos trabalhadores são resultados de uma relação de interdependência e reciprocidade, por que o faturamento de uma das empresas geraria uma relação de moderação nas trocas sociais hipotetizadas em $\mathrm{H} 1$ e $\mathrm{H} 2$ ? Neste estudo, defende-se a ideia de que indivíduos possuem uma capacidade limitada de oferecer a organizações o que elas desejam. Propõe-se aqui que o Comprometimento Afetivo (CA) seja demonstrado por meio de dedicação; e como os indivíduos possuem limitações de tempo $e$ recurso para oferecer às organizações com as quais se relaciona, a troca social recíproca mais intensa tende a ocorrer com a organização na qual o trabalhador identificar uma maior possibilidade de ganhos.

O faturamento da empresa empregadora, com a qual o empregado já possui um vínculo legal trabalhista, embora não represente completamente os ganhos que o indivíduo pode obter na relação com ela, representa um indicativo do potencial da organização para oferecer suporte ao empregado. Empresas empregadoras de maior porte tendem a gerar maiores estímulos sociais, financeiros e emocionais aos empregados do que a organização cliente, e isso poderá levar a uma maior dedicação e investimento do empregado na alocação de seu Comprometimento Afetivo (CA). Em contrapartida, um maior faturamento da empresa empregadora pode limitar o Comprometimento Afetivo (CA) disponível para a troca com a empresa cliente.
Assim, propõe-se que:

a) H3: O faturamento da empresa empregadora modera a relação entre o Suporte Organizacional Percebido da Empresa Empregadora (SOPEE) e o Comprometimento Afetivo (CA) a essa empresa, de forma que um maior faturamento aumenta a relação entre esses dois constructos;

b) H4: O faturamento da empresa empregadora modera a relação entre o Suporte Organizacional Percebido da Empresa Cliente (SOPEC) e o Comprometimento Afetivo (CA) ao cliente, de forma que um maior faturamento diminua a relação entre esses dois constructos.

A Figura 1 abaixo se caracteriza por uma associação positiva entre o Suporte Organizacional Percebido da Empresa empregadora (SOEE) e o Comprometimento Afetivo (CA) a Empresa empregadora (CAEE), bem como uma associação positiva entre o Suporte Organizacional Percebido da Empresa Cliente (SOEC) e o Comprometimento Afetivo (CA) a Empresa Cliente (CAEC). Ambas as associações são moderadas pelo faturamento da empresa.

Figura 1. Modelo de Avaliação de SOPEE, CAEE, SOPEC e CAEC.

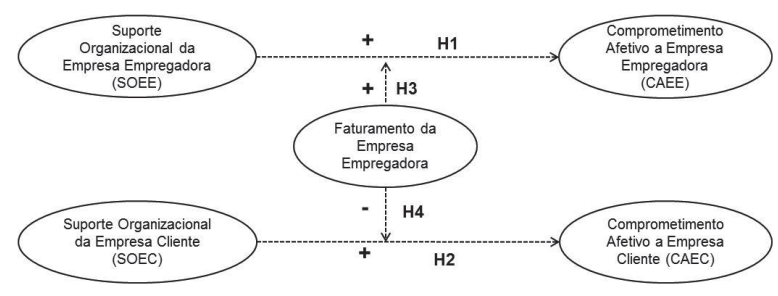

Fonte: Elaborado pelo autor (2016).

\section{Metodologia}

Considerando que o objetivo desta pesquisa é avaliar o papel moderador do faturamento da empresa empregadora na relação entre o Suporte Organizacional Percebido (SOP) e o Comprometimento Afetivo (CA) pelo empregado da empresa empregadora, 
optou-se por uma pesquisa quantitativa descritiva de corte transversal.

O campo de estudo desta pesquisa será o segmento de TI de uma grande empresa do setor de mineração que possui um site na cidade de Vitória no estado do Espírito Santo. Justifica-se a escolha dessa mineradora por possuir uma ampla carteira de empresas empregadoras na modalidade de Outsourcing, distribuídas em diferentes áreas funcionais, além de diferentes níveis de responsabilidade social, contribuindo para análise dos níveis de Comprometimento Afetivo (CA) e Suporte Organizacional Percebido (SOP) pelos Empregados.

Para mensurar o nível de Comprometimento Afetivo (CA) e Suporte Organizacional Percebido (SOP) pelos empregados das empresas empregadoras, diante da organização com a qual possui vínculo trabalhista e da organização cliente, foi elaborado um questionário padrão que foi enviado para 2500 desses empregados. A organização cliente permanecerá a mesma.

Para coletar os dados acerca do constructo Suporte Organizacional Percebido (SOP), adaptou-se o questionário padrão aos modelos de Eisenberger et al. (1986), Williams e Anderson (1991), Wayne, Shore e Liden (1997) e Bendassolli e Borges Andrade (2011). Adicionalmente, o constructo Comprometimento Afetivo (CA) foi adaptado no questionário aos modelos de Meyer, Allen e Smith's (1993), traduzido para o Português por Fontinha, Chambel e Cuyper (2013).

O questionário foi formado por questões demográficas, além de 28 questões a serem respondidas pelos empregados vinculados às empresas empregadoras, divididos em quatro blocos de perguntas: o primeiro e o segundo bloco abordam questões atreladas ao Suporte Organizacional Percebido (SOP) pelo empregado da empresa empregadora; o primeiro bloco se refere à organização com a qual o empregado possui vínculo trabalhista, e o segundo bloco se refere à organização cliente. Por fim, o terceiro e o quarto bloco abordam questões atreladas ao Comprometimento Afetivo (CA) do empregado da empresa empregadora; o terceiro bloco se refere à organização no qual o empregado possui vinculo trabalhista $e$ o quarto bloco se refere à organização cliente. Nesses blocos utilizou-se a escala de Likert (1967), que apresenta em seu modelo 5 níveis de concordância (discordo totalmente a concordo totalmente).

A análise dos resultados foi conduzida da seguinte forma: inicialmente, conduziu-se um teste de validade convergente, de avaliação do ajuste do modelo e de viés de método comum. Esses testes foram requisitos para avaliar se o modelo se mostrava adequado para o teste das hipóteses. Na sequência, as hipóteses foram testadas usando um modelo de análise de regressão hierárquica.

\section{Análise dos Resultados}

A análise dos resultados foi realizada em duas etapas. Inicialmente, conduzimos uma análise fatorial confirmatória para avaliar a validade discriminante dos construtos. Esta etapa foi realizada usando o software LISREL 8.80. Em seguida, foi conduzida uma análise do Goodness of fit com o modelo teórico de 5 variáveis, no qual forçou-se um alinhamento entre os itens e seus respectivos constructos. Este modelo foi comparado a modelos alternativos. Na tabela 1 apresentam-se os resultados deste teste.

Tabela 1: Resultados da Análise Fatorial Confirmatória

\begin{tabular}{|c|c|c|c|c|c|}
\hline Modelo & $\chi 2$ & DF & IFI & CFI & RMSEA \\
\hline Modelo de Cinco Fatores & 856,31 & 522 & 0,97 & 0,97 & 0,04 \\
\hline Modelo de Quatro Fatores: SOP Cliente e SOP Empregador Combinados & 2035,44 & 524 & 0,88 & 0,88 & 0,11 \\
\hline $\begin{array}{l}\text { Modelo de Quatro Fatores: Comp. do Cliente e } \\
\text { Comp. do Empregador Combinados }\end{array}$ & 2128,92 & 524 & 0,89 & 0,89 & 0,12 \\
\hline Modelo de um fator & 4392,15 & 526 & 0,71 & 0,71 & 0,19 \\
\hline
\end{tabular}


Conforme pode ser identificado na tabela 1, o modelo de 5 fatores que usamos nesta pesquisa mostrou um grau de ajuste bastante satisfatório $(\chi 2=856,31$; $\mathrm{df}=522 ; \mathrm{IFI}=0,97 ; \mathrm{CFI}=0,97$, RMSEA $=0,04)$. $\mathrm{O}$ ajuste deste modelo se apresentou como mais satisfatório que os encontrados nos modelos alternativos, segundo os critérios de Hu e Bentler (1999). Para testar o viés de método comum, nós desenvolvemos o teste de um fator de Harman. O teste de diferença de $\mathrm{X} 2$ indicou que o modelo de um fator mostrou-se significativamente mais fraco que o de seis fatores (diferença do
$\mathrm{X} 2(\mathrm{df}=7)=3756,02, \mathrm{p}<0,01)$. Esse resultado permite afirmar que não houve a presença de viés de método comum nos dados.

Os índices encontrados e o teste de viés de método comum permitem dizer que o modelo se mostrou adequado para que se procedesse ao teste das hipóteses. Na sequência, realizamos uma análise preliminar dos dados, de forma a compreender como as principais variáveis se comportaram em termos de médias, desvio padrão e correlações. A tabela 2 sintetiza esses resultados.

Tabela 2: Estatística Descritiva Correlacionada

\begin{tabular}{|c|c|c|c|c|c|c|c|}
\hline VARIÁVEL & MÉDIA & DP & $\mathbf{1}$ & 2 & 3 & 4 & 5 \\
\hline 1. SOP Empregador & 3,1 & 0,97 & $(0,88)$ & & & & \\
\hline 2. SOP Cliente & 2,64 & 0,98 & $0,13^{*}$ & $(0,87)$ & & & \\
\hline 3. Comprometimento Empregador & 2,57 & 1,23 & $0,33 * *$ & 0,09 & $(0,93)$ & & \\
\hline 4. Comprometimento Cliente & 2,62 & 1,21 & 0,07 & $0,34 * *$ & $0,14^{*}$ & $(0,89)$ & \\
\hline 5. Faturamento & 724,4 & 1633,11 & $0,33 * *$ & $0,36 * *$ & 0,08 & 0,09 & $(0,90)$ \\
\hline
\end{tabular}

Nota: Os números em parênteses são em Cronbach's com ** de significância a grau 0.01

Na próxima etapa da análise, o método de análise de regressão hierárquica foi usado para testar as hipóteses. De forma a lidar com uma multicolinearidade potencial entre as variáveis (AIKEN; WEST, 1991), todas as variáveis independentes, moderadoras e de controle foram padronizadas antes que a análise fosse conduzida. Em seguida, nós testamos as relações entre os suportes organizacionais da empresa empregadora e da cliente com os comprometimentos afetivos em relação às respectivas organizações. Os resultados dessa análise se encontram apresentados na tabela 3.

No Modelo 1, foram inseridas as variáveis de controle como primeiro passo da regressão. Nesta etapa, duas variáveis de controle, nível hierárquico $(\beta=0,17$, $\mathrm{p}<0,05)$ e tempo de empresa $(\beta=0,13, \mathrm{p}<0,05)$ se mostraram associadas ao Comprometimento Afetivo (CA) em relação à empresa empregadora. Este resultado sugere que os indivíduos que alçaram posições superiores na carreira e os que estão trabalhando na empresa há mais tempo apresentam maior probabilidade de se mostrarem comprometidos afetivamente em relação à organização com a qual possuem um vínculo empregatício.
No segundo modelo, foram inseridas as variáveis independentes (Suporte Organizacional Percebido (SOP) da empresa empregadora e da cliente). O Suporte Organizacional Percebido (SOP) da empresa empregadora se mostrou positivamente associado ao Comprometimento Afetivo (CA) a essa mesma organização $(\beta=0,31, p<0,01)$, o que leva à não rejeição da Hipótese 1. Isto significa que o suporte que a empresa empregadora oferece a seu funcionário tende a fazer com que ele se sinta conectado em termos emocionais à organização.

No Modelo 3, a interação Suporte Organizacional Percebido (SOP) do Empregador x Faturamento do Empregador se relacionou positiva e significativamente ao Comprometimento Afetivo (CA) em relação ao Empregador $(\beta=0,20, p<0,01)$. Este resultado indica que, para a amostra pesquisada, quanto maior o faturamento da empresa empregadora, mais forte será a probabilidade de que o Suporte Organizacional Percebido (SOP) do Empregador gere maior Comprometimento Afetivo (CA) em relação ao Empregador. Assim, a hipótese 3 também não foi rejeitada. 
Tabela 3: Resultados da Análise de Regressão Hierárquica

\begin{tabular}{|c|c|c|c|c|c|c|}
\hline \multicolumn{3}{|c|}{ Comprometimento Afetivo (CA) do Empregador } & \multicolumn{4}{|c|}{ Comprometimento Afetivo (CA) do Cliente } \\
\hline VARIÁvel DePENDENTE & $\begin{array}{c}\text { Modelo } 1 \\
\text { AmostRA } \\
\text { Completa }\end{array}$ & Modelo 2 & Modelo 3 & Modelo 4 & Modelo 5 & Modelo 6 \\
\hline \multicolumn{7}{|l|}{ Passo 1 : Variáveis de Controle } \\
\hline Nível Hierárquico & $0,17^{*}$ & $0,13^{*}$ & 0,10 & 0,08 & 0,07 & 0,07 \\
\hline Tempo na Empresa & $0,13^{*}$ & 0,09 & 0,08 & 0,07 & 0,04 & 0,04 \\
\hline Gênero & $-0,12$ & $-0,03$ & 0,01 & 0,02 & 0,01 & 0,01 \\
\hline Idade & 0,08 & 0,04 & 0,03 & 0,02 & 0,02 & 0,02 \\
\hline$\Delta \mathrm{R} 2$ & 0,10 & 0,10 & 0,10 & 0,02 & 0,02 & 0,02 \\
\hline \multicolumn{7}{|l|}{ Passo 2 : Variáveis Independentes } \\
\hline SOP Empregador & & $0,31^{* * *}$ & $0,33 * *$ & & $0,19 *$ & $0,20 *$ \\
\hline SOP Cliente & & $0,21^{*}$ & $0,21 *$ & & $0,33 * *$ & $0,33 * *$ \\
\hline$\Delta \mathrm{R} 2$ & & 0,16 & 0,16 & & 0,11 & 0,11 \\
\hline \multicolumn{7}{|l|}{ Passo 3 : Efeitos de Interação } \\
\hline SOP Empregador x Faturamento E & & & $0,20 * *$ & & & 0,03 \\
\hline SOP Cliente $\mathrm{x}$ Faturamento E & & & 0,02 & & & $-0,13$ \\
\hline \multicolumn{7}{|l|}{$\Delta \mathrm{R} 2$} \\
\hline \multicolumn{7}{|l|}{ Modelo Geral } \\
\hline $\mathrm{R} 2$ & 0,11 & 0,25 & 0,26 & 0,03 & 0,11 & 0,15 \\
\hline $\mathrm{N}$ & 197 & 197 & 197 & 197 & 197 & 197 \\
\hline
\end{tabular}

Posteriormente a esse conjunto de análises iniciais, procedeu-se ao teste das relações que envolvem o Comprometimento Afetivo (CA) em relação à empresa cliente como variável dependente. No quarto passo da regressão, iniciou-se a análise inserindo as variáveis de controle no modelo. Os resultados mostraram que nenhuma dessas variáveis (nível hierárquico, tempo de empresa, gênero e idade) mostraram associação com o Comprometimento Afetivo (CA) em relação à empresa Cliente.

No modelo 5, testamos a associação com as variáveis independentes (Suporte Organizacional Percebido (SOP) da empresa empregadora e da cliente). O Suporte Organizacional Percebido (SOP) da empresa cliente relacionou-se positiva e significativamente associado ao Comprometimento Afetivo (CA) a essa mesma organização ( $\beta=0,33, p<0,01)$, o que permitiu não rejeitar a Hipótese 2. Esta relação sugere que o apoio oferecido pela empresa cliente ao trabalhador alocado pela empresa contratada tende a se reverter em vínculo emocional em relação a esse cliente.

Finalmente, no sexto e último modelo a interação Suporte Organizacional Percebido (SOP) da empresa cliente $\mathrm{x}$ Faturamento da Empresa Empregadora não se mostrou associada ao Comprometimento Afetivo (CA) da empresa cliente $(\beta=-0,13, p>0,05)$. Este resultado indica que, para a amostra pesquisada neste estudo, um maior Faturamento da empresa Empregadora não enfraquece o impacto do Suporte Organizacional Percebido (SOP) da empresa Cliente no Comprometimento Afetivo (CA) em relação a essa mesma empresa. Assim, a hipótese 4 foi rejeitada. 
Como o estudo em questão adotou análise de moderações, optou-se por seguir as recomendações de Aiken e West (1991) de realizar um teste adicional para avaliar os resultados da hipótese de moderação não rejeitada. Sendo assim, foram plotadas as equações das regressões em distintos níveis de faturamento da empresa empregadora, de forma a possibilitar uma melhor interpretação dos efeitos moderadores desse faturamento nas relações entre os suportes organizacionais e os comprometimentos afetivos estudados. Essa análise é apresentada na figura 2, que representa, a hipótese 3.

Figura 2. Interação entre SOP do Empregador e o Comprometimento do Empregador

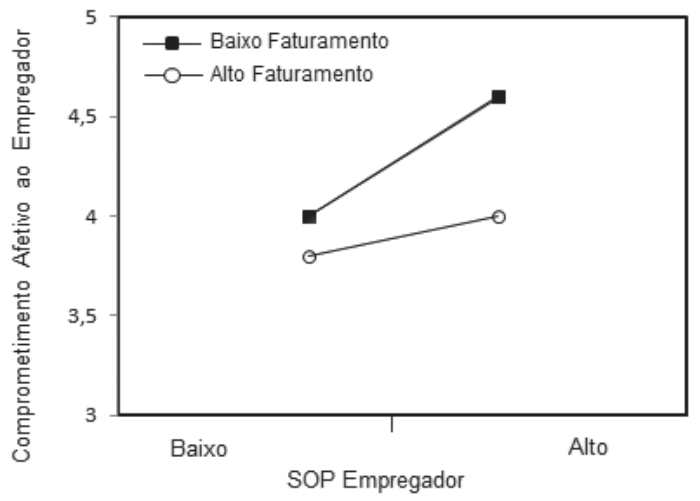

A figura 2 mostra o efeito moderador do faturamento da empresa empregadora na relação entre o suporte organizacional oferecido pela empresa empregadora e o Comprometimento Afetivo (CA) em relação a essa organização. Como é possível notar, quando o faturamento se apresenta em níveis mais elevados, a influência do Suporte Organizacional Percebido (SOP) da empresa empregadora no Comprometimento Afetivo (CA) em relação a essa mesma empresa foi maior, o que caracteriza uma relação de moderação.

Além de plotar as interações significantes, foi conduzida uma análise de declives simples para buscar evidências adicionais para o efeito moderador. Os resultados mostraram que a relação entre a relação entre o Suporte Organizacional Percebido (SOP) da empresa empregadora e o Comprometimento Afetivo (CA) em relação à empresa empregadora, sob a condição de faturamento alto, foi significativamente diferente de zero (simple slope $=0,25, \mathrm{t}=4,86, \mathrm{p}<0,01$ ). Em contraste, em condições de faturamento baixo, a citada relação não se mostrou significante (simple slope $=0,01, t=0,92, p=0,23$, não significante). Na sequência, esses resultados são discutidos à luz da literatura existente sobre o tema.

\section{Discussão}

O objetivo desta pesquisa foi avaliar o papel moderador do faturamento da empresa empregadora na relação entre o Suporte Organizacional Percebido (SOP) e o Comprometimento Afetivo (CA) pelo empregado da empresa empregadora. Conforme previsto, pelos resultados encontrados, foram encontradas evidências de que faturamento da mesma empresa modera a relação entre os dois constructos citados anteriormente. Adicionalmente, o Suporte Organizacional Percebido (SOP) mostrou-se associado positivamente ao Comprometimento Afetivo (CA) ao empregado da empresa empregadora, tanto em relação ao cliente quanto a própria empresa.

Os resultados desta pesquisa se encontram em linha com a afirmação teórica de que trabalhadores tendem a apresentar maior Comprometimento Afetivo (CA) quando percebem que estão recebendo algum tipo de suporte organizacional (DE ALLEN et al., 1999; EISENBERGER et al., 1986; HUTCHISON, 1997; MEYER; ALLEN, 1997). Adicionalmente, os resultados encontrados nesta mesma relação sob a ótica da empresa empregadora e da empresa cliente, se mostraram equivalentes, o que reforça a relação positiva teórica entre estes dois constructos. Segundo Blau (1964), a Teoria da Troca Social (RANK; LECROY, 1983) tem se mostrado como um paradigma influente nas relações de trabalho, estando este conceito diretamente ligado a reciprocidade nas relações (GÖBEL; VOGEL; WEBER, 2013), também em linha com os resultados encontrados. Sendo assim, este estudo se soma a literatura citada no sentido de mostrar evidências de que o princípio da Troca Social que leva a associação entre o Suporte Organizacional e o Comprometimento Afetivo (CA) se mostrou relevante para as díades Trabalhador-Empresa Empregadora e Trabalhador-Empresa Contratante.

Entretanto, os estudos realizados até o momento não haviam explorado a influência do faturamento da empresa empregadora na relação entre o Suporte Organizacional Percebido (SOP) oferecido por ambas 
as organizações e os respectivos Comprometimentos Afetivos obtidos por elas. A partir dessa lacuna de pesquisa, este estudo examinou a influência do faturamento da empresa empregadora como papel moderador na relação entre o Suporte Organizacional Percebido (SOP) e o Comprometimento Afetivo (CA).

Desta forma, ao analisar a literatura percebe-se que os resultados desta pesquisa se encontram parcialmente em linha com o pressuposto da Teoria de Suporte Organizacional (BARAN et al., 2012) e os argumentos de Moen (1999), segundo os quais empresas de maior porte possuem mais recursos financeiros $e$ tecnológicos para investimento no empregado, resultando em maior Comprometimento Afetivo (CA). Os resultados desses estudos apoiam a ideia de que quanto maior o faturamento da empresa que foi contratada, maior a chance de que o Suporte Oferecido se reverta em uma relação afetiva mais forte entre a empresa e seu empregado. Uma explicação para esse fato seria a ideia de que os empregados enxergam empresas com maior faturamento como detentora de recursos mais amplos (financeiros e não financeiros) que poderão no futuro ser objeto de trocas sociais relevantes. Em outras palavras, a empresa tende a ser interpretada como mais promissora no critério de estar apta a retribuir no futuro eventuais esforços que o trabalhador decida oferecer em suas relações de trabalho.

Por outro lado, um resultado não esperado foi encontrado nesta pesquisa. Diferentemente do que se proporia pela Teoria da Troca Social (BLAU, 1964), o faturamento da empresa empregadora não mostrou efeito moderador negativo na relação entre o Suporte Organizacional Percebido (SOP) da empresa cliente com o Comprometimento Afetivo (CA) em relação a essa empresa. Esperava-se esse resultado a partir da lógica de que quando a empresa empregadora em uma relação de Outsourcing possui maior porte (o que inclui seu faturamento), o esforço da empresa cliente em fornecer suporte perderia força em termos de capacidade de gerar maiores níveis de Comprometimento Afetivo (CA). Isto levaria a um pensamento de que as empresas clientes deveriam investir mais no oferecimento de suporte quando a empresa contratada fosse de menor porte. Ao não identificar suporte para esse achado, pode-se sugerir que a decisão de oferecimento ou não de um determinado nível de suporte organizacional aos empregados da contratada com fins de geração de
Comprometimento Afetivo (CA) não se altera em função do nível de faturamento da empresa empregadora.

\section{Conclusão}

Em conjunto, os resultados sugerem que a teoria da Troca Social se mostra como uma lente adequada para explicar a maneira como os empregados de empresas contratadas em um contexto de dupla relação laboral de Outsourcing gerenciam os fluxos de reciprocidade se suporte/Comprometimento Afetivo (CA) em relação a ambas empresas. A análise mostra, em consonância com a literatura anterior, que ambas as empresas (empregadora e cliente) obtém retorno dos empregados em termos de Comprometimento Afetivo (CA). O estudo também ressalta a importância de que esse suporte seja oferecido especialmente por empresas de Outsourcing de maior porte, dado que o vislumbrar de futuras possibilidades de trocas sociais com essa empresa empregadora pode ampliar a possibilidade de que o suporte oferecido se reverta em Comprometimento Afetivo (CA).

\subsection{Limitações e recomendações de pesquisa e práticas}

Os resultados encontrados nesta pesquisa sugerem uma relação positiva entre o Suporte Organizacional Percebido (SOP) pelo empregado da empresa contratada e o Comprometimento Afetivo (CA). Adicionalmente, o Faturamento da empresa contratada modera a relação entre estes dois constructos.

Primeiro, não se encontraram evidências que explicassem a inexistência de moderação do faturamento de empresa cliente na relação entre o Suporte Organizacional em relação a empresa empregadora e o Comprometimento Afetivo (CA) em relação a essa mesma empresa. Este resultado pode ter como origem algumas limitações desta pesquisa. A seguir apontam-se algumas dessas limitações e propõe-se sugestões de pesquisas futuras que visem a uma melhor replicação do fenômeno.

Não analisamos nesta pesquisa a localidade do posto de trabalho no qual os empregados estão (se nas dependências da contratante, da contratada ou em algum local diferente) e se essas pessoas utilizam no 
dia-a-dia elementos simbólicos que leve a uma maior identificação com a empresa cliente, tais como uniforme e crachá. Pesquisas futuras são necessárias para superar essas limitações e contribuir na avaliação do nível de importância dessas variáveis como moderadoras. É possível que uma maior identificação simbólica com a empresa cliente apresente efeito moderador que se explicado e não foi encontrado nesta pesquisa.

Segundo, realizou-se uma pesquisa no contexto de apenas uma empresa contratante do setor de mineração, situada na cidade de Vitória, no estado do Espírito Santo. Sugere-se que o modelo apresentado neste estudo seja aplicado em empresas de outros segmentos de atuação. Além disto, todos os correspondentes residem em cidades do Brasil. Levando-se em consideração aspectos culturais, sociais e históricos quem pode impactar na percepção do Suporte Organizacional Percebido (SOP) pelo empregado da empresa contratante, bem como no faturamento da empresa contratada, sugere-se realizar novos estudos com amostras que contemplem diferentes empresas empregadoras, de distintos setores e também estudos em outros países.

Terceiro, deve-se considerar a limitação da abordagem quantitativa do estudo, nos quais os resultados são interpretados exclusivamente de forma estatística. Pelo cunho subjetivo da pesquisa, estudos qualitativos associados à abordagem quantitativa como o Grounded Theory, poderiam proporcionar a geração de proposições teóricas que poderiam ser tratadas em estudos quantitativos posteriores.

Quarto, o estudo aqui apresentado não permite realizar inferências de causalidade. O recorte transversal dos dados traz uma limitação para a análise, que se limita a realizar uma descrição de associações. Futuras pesquisas poderiam adotar um recorte longitudinal, o que conferiria possibilidades de realizar análises de causalidade.

\subsection{Sugestões para a prática}

Na prática, sugere-se que líderes de empresas empregadoras na modalidade de Outsourcing, especialmente se forem de alto nível de faturamento, invistam em Suporte Organizacional com o intuito de obter retorno em termos de Comprometimento Afetivo (CA) por parte do Empregado. Em contrapar- tida, sugere-se que líderes de empresas contratantes invistam em Suporte Organizacional independente do nível de faturamento da empresa empregadora. Por meio desses investimentos, tais organizações tendem a alcançar um maior Comprometimento Afetivo (CA) do empregado, podendo se reverter em um melhor desempenho profissional. Por fim, recomenda-se que as organizações que realizam investimentos em suporte a seus funcionários ou a empregados de empresas terceiras, invistam não somente em elementos de suporte, mas também na divulgação de tais aspectos em ações de endomarketing. Isto seria relevante pelo fato de que os trabalhadores são agentes passivos nesse processo, 0 que significa dizer que cabe à organização que realiza o investimento em suporte a tarefa de divulgação de tais elementos de forma que eles possam apresentar os retornos esperados.

\section{REFERÊNCIAS}

AIKEN, Leona S.; WEST, Stephen G.; RENO, Raymond

$\mathrm{R}$. Multiple regression: Testing and interpreting interactions. Sage, 1991.

ALLEN, Natalie J.; MEYER, John P. Affective, continuance, and normative commitment to the organization: An examination of construct validity. Journal of Vocational

Behavior, v. 49, n. 3, p. 252-276, 1996.

; MEYER, John P. Commitment in the workplace:

Theory, research and application. [s.l.].Thousand Oaks, 1997.

AXELROD, R.; DION, D. The further evolution of cooperation. Science, v. 242, n. 4884, p. 1385-1390, 1988.

BARAN, Benjamin E.; SHANOCK, Linda Rhoades; MILLER, Lindsay R. Advancing organizational support theory into the twenty-first century world of work. Journal of Business and Psychology, v. 27, n. 2, p. 123-147, 2012.

BIDO, Diógenes de Souza et al. Mensuração com indicadores formativos nas pesquisas em administração de empresas: como lidar com a multicolinearidade entre eles? Administração: Ensino e Pesquisa, v. 11, n. 2, p. 245$269,2010$. 
BLAU, Peter Michael. Exchange and power in social life. [s.1.]:Transaction Publishers, 1964.

BUTCH, Nicholas P. et al. Strong surface scattering in ultrahigh-mobility Bi 2 Se 3 topological insulator crystals. Physical Review B, v. 81, n. 24, p. 241301, 2010.

CHIN, W. W. The partial least squares approach to structural equation modeling. Modern Methods for Business Research, v. 295, n. 2, p. 295-336, 1998.

COOK, Karen S. et al. Social exchange theory.

Missouri: Springer Netherlands, 2013.

COYLE-SHAPIRO, Jacqueline A.M.; MORROW, Paula C. Organizational and client commitment among contracted employees. Journal of Vocational Behavior, v. 68, n. 3, p. 416-431, 2006.

CROPANZANO, Russell; MITCHELL, Marie S. Social exchange theory: An interdisciplinary review. Journal of management, v. 31, n. 6, p. 874-900, 2005.

DE JONG, Jeroen; SCHALK, René. Extrinsic motives as moderators in the relationship between fairness and workrelated outcomes among temporary workers. Journal of Business and Psychology, v. 25, n. 1, p. 175-189, 2010.

EDWARDS, Martin R. HR perceived organisational support and organisational identification: an analysis after organisational formation. Human Resource Management Journal, v. 19, n. 1, p. 91-115, 2009. EISENBERGER, R.; HUNTINGTON, R; HUTCHINSON, S.; SOWA, D. Perceived organizational support. Journal of Applied Psychology, v. 71, n. 3, p. 500-507, 1986.

; FASOLO, Peter; DAVIS-LAMASTRO, Valerie.

Perceivedorganizational support and employee diligence, commitment, and innovation. Journal of applied psychology, v. 75 , n. 1 , p. 51,1990

EMERSON, Richard M. Social exchange theory. Annual review of sociology, p. 335-362, 1976.

FERNANDES, Maria Elizabeth Rezende; CARVALHO NETO, Antônio Moreira de. Gestão dos múltiplos vínculos contratuais nas grandes empresas brasileiras. Revista de Administração de Empresas, v. 45, n. SPE, p. 48-59, 2005.
FONTINHA, Rita; CHAMBEL, Maria José; DE CUYPER, Nele. Training and the commitment of outsourced information technologies' workers: Psychological contract fulfillment as a mediator. Journal of Career Development, p. 0894845313495587, 2013.

GALLAGHER, Daniel G.; PARKS, Judi McLean. I pledge thee my troth contingently: Commitment and the contingent work relationship. Human Resource Management Review, v. 11, n. 3, p. 181-208, 2001. GEORGE, Elizabeth; CHATTOPADHYAY, Prithviraj. One foot in each camp: The dual identification of contract workers. Administrative Science Quarterly, v. 50, n. 1, p. 68-99, 2005.

\section{GERGEN, K. J. The psychology of behavioral} exchange. Reading, MA: Addison-Wesley, 1969.

GIUNCHI, Marianna; CHAMBEL, Maria José; GHISLIERI, Chiara. Contract moderation effects on temporary agency workers' affective organizational commitment and perceptions of support. Personnel Review, v. 44, n. 1, p. 22-38, 2015.

GÖBEL, Markus; VOGEL, Rick; WEBER, Christiana. Management research on reciprocity: A review of the literature. BuR-Business Research, v. 6, n. 1, p. 34-53, 2013.

HAIR JUNIOR, Joseph F. et al. Fundamentos de métodos de pesquisa em administração. São Paulo: Bookman Companhia, 2005.

HU, L.T; BENTLER, P.M. Cutoff criteria for fit indexes in covariance structure analysis: conventional criteria versus new alternatives. Structural Equation Modeling, v. 6, n. 1, p. $1-55,1999$

LAWLER, E.J.; THYE, S. R. Bringing emotions into social exchange theory. Annual Review of Sociology, n.25, p.217-244, 1999. Disponível em: <http://www.jstor.org/ stable/223504 > . Acesso em: 15 mar. 2016

LIKERT, Rensis. The method of constructing and attitude scale. Methods and Trchniques in Business Research. New York: New York University, 1967.

MEYER, John P.; ALLEN, Natalie J. A three-component conceptualization of organizational commitment. Human resource management review, v. 1, n. 1, p. 61-89, 1991. 
MOEN, O. The relationship between firm size, competitive advantages and export performance revisited. International Small Business Journal, v.18, n. 1, p. 53-72, 1999.

MOLM, L. D. Dependence and risk: Transforming the structure of social exchange. Social Psychology Quarterly, n.57, p.163-176, 1994.

PERIN, Marcelo Gattermann; SAMPAIO, Cláudio Hoffmann. Orientação para o mercado, porte empresarial e performance. RAE-Revista de Administração de Empresas, v. 44, n. 3, p. 76-88, 2004.

RANK, M. R.; LECROY, C. W. Toward a Multiple Perspective in Family Theory and Practice: The Case of Social Exchange Theory, Symbolic Interactionism, and Conflict Theory.

Family Relations, v.32, n.3, p.441-448, 1983.

RHOADES, Linda; EISENBERGER, Robert; ARMELI, Stephen. Affective commitment to the organization: the contribution of perceived organizational support. Journal of applied psychology, v. 86, n. 5, p. 825, 2001.

Perceived organizational support: a review of the literature. Journal of applied psychology, v. 87, n. 4, p. 698-714, 2002.
SHORE, Lynn M.; WAYNE, Sandy J. Commitment and employee behavior: comparison of affective commitment and continuance commitment with perceived organizational support. Journal of applied psychology, v. 78, n. 5, p. $774,1993$.

UHL-BIEN, M.; MASLYN, J. 2003. Reciprocity in managersubordinate relationships: Components, configurations, and outcomes. Journal of Management, n.29, p.511532, 2003.

VAN BREUGEL, Gerla; VAN OLFFEN, Woody; OLIE, René. Temporary liaisons: the commitment of 'temps' towards their agencies*. Journal of Management Studies, v. 42, n. 3, p. 539-566, 2005.

VEITCH, Robert W.D.; COOPER-THOMAS, Helena

D. Tit for tat? Predictors of temporary agency workers' commitments. Asia Pacific Journal of Human

Resources, v. 47, n. 3, p. 318-337, 2009.

WAYNE, Sandy J.; SHORE, Lynn M.; LIDEN, Robert C. Perceived organizational support and leader-member exchange: A social exchange perspective. Academy of Management Journal, v. 40, n. 1, p. 82-111, 1997. 